\title{
Challenges of visually impaired students in the use of virtual learning platforms at Wesley College of Education in Ghana
}

Amaniampong, Philemon

Methodist College of Education Akim Asene-Aboabo, Oda, Ghana (philemonamaniampong@yahoo.com)

Nyavor, Michael

Methodist College of Education Akim Asene-Aboabo, Oda, Ghana (nyamicky2014@gmail.com)

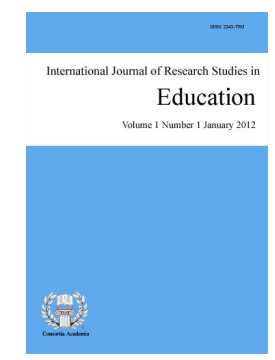

ISSN: $2243-7703$ Online ISSN: 2243-7711

OPEN ACCESS

\section{Abstract}

The purpose of the study was to find out the challenges of visually impaired students in the use of virtual learning platforms at Wesley College of Education. The research design adopted was case study. The sample size was 4 where participants were selected using the purposive sampling technique. Semi-structured interview guide was used to collect data. The study revealed that the use of virtual platforms allows students with visual impairment learn at their own pace, reduce fear of talking in the classroom, have access to open learning. However, virtual learning does not cater for individual learning styles, clarify and explain concepts to meet the unique needs of students, inadequate materials to access the platforms, interfaces of web pages inaccessible, lack of braille version of online instructions to compensate for students who had problem virtually, and poor internet access. It was recommended that tutors provide braille version of their virtual instructions, vary their mode of delivery to meet the learning styles of learners virtually, adapt interfaces of virtual platforms for easy access by students with visual impairment.

Keywords: virtual learning; student teacher; visual impairment; e-learning; web 


\section{Challenges of visually impaired students in the use of virtual learning platforms at Wesley College of Education in Ghana}

\section{Introduction}

Until the outbreak of covid19, teaching and learning in our Ghanaian schools is conducted in a face-to-face manner. However, the inception of covid19 pandemic has compelled both learners and teachers to use virtual means to conduct teaching and learning of which majority are first time users. It became mandatory for all learners including the visually impaired to learn virtually. Let's consider the concept visually impaired and how they learn virtually.

Visually impaired is a person who has a limited or total loss in the vision which interferes in the use of the eye to perform task. This impairment if not reversible or correctible by the use of glasses or surgery affect the academic pursuit of the child. Visual impairment includes a child who is blind therefore cannot use vision for learning or the low vision who has difficulty accomplishing visual tasks, but they can learn through the visual sense by the use of various special technologies and teaching techniques. Globally, it is estimated that 2.2 billion people of all ages may have vision impairment. Majority of the visual problems ( 92 percent) are caused by uncorrected refractive error which can be easily corrected with a pair of eyeglasses. Among those, at least one billion people suffer from moderate or severe distance vision impairment or blindness that could have been prevented or has yet to be addressed (WHO, 2019).

The visually impaired have difficulty obtaining information as compared to others because the greater proportion of information is acquired through vision which is limited or absent in their case. This therefore means in accessing information through any medium be it virtual, face-to-face, copies of books, there is the need to use different formats that will address the unique needs of the visually impaired. Visually impaired students can thrive well in the use of virtual learning provided there are adaptations made to support their usage. What then is virtual learning as the focus of the study?

Virtual learning can be viewed as the use of educational technologies to design, deliver, and manage both formal and informal learning and knowledge sharing at any time, any pace and any place. Virtual learning is acquired via interaction with digitally delivered content, network-based services and tutoring support often with any type of online tool and media including the internet, intranets, extranets, simulations and games, virtual worlds, clouds, satellite broadcasts, and web platforms (Schutt \& Linegar, 2013; Pelet \& Lecarte, 2013). It is carried out through the use and integration of electronic discourses, such as email, portal, downloadable-executable-file, face-book, social networking, web platforms, electronic dissertations and e-portfolios, among others (Bouchard, 2011; Weller, 2010). Mobile learning which is the ability to obtain or provide educational content on personal pocket devices such as PDAs, smart phones and mobile phones, is also a form of virtual learning (Kharbach, 2013).

Rationale for virtual learning could be seen in the fact that the world of the twenty-first century can aptly be called an e-driven world (Oye, A.Lahad, Madar \& Ab.Rahim, 2012). E/virtual technologies have brought profound changes to all facets of life. In order to equip students with the necessary skills and knowledge to foster the growth of independence, creativity and lifelong learning, schools should use virtual learning to provide relevant experiences to students'. The use of online learning environments provides learners opportunities for flexibility, interaction and collaboration (Gedera, Williams \& Wright, 2013). Also, virtual learning provides both teachers and students ways of exploring and constructing knowledge outside the four walls of the classroom.

In extension of the relevance of the use of virtual learning Hameed, Badii, and Cullen (2008) cited in Arkorful and Abaidoo, (2014) includes the following: 
$>\quad$ It is flexible when issues of time and place are taken into consideration. Every student has the luxury of choosing the place and time that suits him/her. According to Smedley (2010), the adoption of e-learning provides the institutions as well as their students or learners the much flexibility of time and place of delivery or receipt of according to learning information.

$>\quad$ Virtual learning provides opportunities for relations between learners by the use of discussion forums. Through this, e-learning helps eliminate barriers that have the potential of hindering participation including the fear of talking to other learners. E-learning motivates students to interact with other, as well as exchange and respect different point of views. E-learning eases communication and also improves the relationships that sustain learning. Wagner et al (2008) note that e-Learning makes available extra prospects for interactivity between students and teachers during content delivery.

$>$ E-learning always takes into consideration the individual learners differences. Some learners, for instance prefer to concentrate on certain parts of the course, while others are prepared to review the entire course.

$>\quad$ The use of e-Learning allows self-pacing. For instance, the asynchronous way permits each student to study at his or her own pace and speed whether slow or quick. It therefore increases satisfaction and decreases stress

One great thing about online learning is that any student with a computer and an internet connection can take classes without actually having to go to a classroom. This therefore means students with visual impairment as far as they are having computers, and other technological devices that are adaptable to their needs can thrive well in the use of online services. When virtual learning is programmed to meet the unique needs of the visually impaired students it removes all the difficulties of getting to school and into their classrooms. This reduce the challenges they face in getting about their environment which is unstructured in most of our Ghanaian schools. With adaptive technologies like voice-to-text software, audio recordings, screen magnifiers and braille keyboards, visually impaired students can realize their full potential.

There are many national and international policies that pronounce the creation of access to all including those with disabilities. Some of these policies and conventions include the Salamanca Statement, Inclusive Education policy of Ghana, Standard Rules on the Equalization of Opportunities for Persons with Disabilities, the constitution of Ghana. These conventions admonish countries across the world including Ghana to bridge the gap between those with disabilities and those without. In effective use of virtual learning, there should be equity for all learners where they are provided access to maximize their potentials than over reliance on human support which could be absent at the time of the use of a particular service. In bridging the virtual gap for the visually impaired there is the need to provide assistive technologies such as audio-video tape, CD-ROM and making computer and web interfaces more accessible. This is in line with the Universal Design and Access Theory which was popularized by Herriot in 2006. To this end, how do the visually impaired fair in the use of virtual learning?

Many studies have outlined challenges students faced in the use of virtual learning in general terms and specifically the visually impaired students. In general terms, Sarker, Mahmud, Islam, and Islam (2019) asserted that inadequate ICT infrastructure is a challenge capable of hindering e-learning implementation success. Again, the challenges to implementing its e-learning system range from inadequate ICT infrastructure, poor ICT skills of some lecturers, inadequate funds for implementation, inadequate ICT staff, high cost of accessibility of e-learning by nonresidential students and low motivation for lecturers to accept and use e-learning. Other challenges students can encounter in the use of virtual learning is the low motivation in the use of virtual learning, unavailability of electricity in parts of the country to support their use of phones and laptops to aid in learning, the poor or no network in parts of the country as most of the students are resident home. These challenges apply to all including those with disabilities.

Aside the challenges outlined above which is applicable to all, studies have also, outlined disability specific 
challenges that students with visual impairment face in virtual learning. Studies from Craven and Brophy (2003), Gerber (2003) and Leporini and Paterno (2004) revealed that while there has been much transformation in universal access to technology, students with visual impairment still struggle with poorly designed computer interfaces that continue to lag behind in some web design features. Gerber (2003) and Craven and Brophy (2003) in their exposition on the challenges visually impaired students face in using virtual learning mention that most of the adaptive technologies used by students with visual impairment only help them to navigate the internet in a linear and serial pattern. Most of these web pages are accessible to the visually impaired but not usable by them because of the interfaces. There are instances that the visually impaired is deny both access and usability due to the web page designs which is sophisticated and include visual elements such as graphics, hyperlinks and pop-up windows that pose challenge to them. In case the visually impaired is considered at all, the web designers tend to address only accessibility issues, and ignore the equally important usability dimension of e-learning tools' (Leporini \& Paterno 2004).

In another study conducted by the American Foundation for the Blind (2008), the findings indicated that features of online educational tools pose significant problems for those using assistive technology such as screen reading or screen magnification software. About one third of participants who used assistive technology to access online educational tools reported the experiences as unreliable and unsuccessful. For instance, chat features and assessments that involved matching were not compatible with access software.

Fichten, Asuncion, Barile, Ferraro, and Wolforth (2009) in a study conducted at Canadian Colleges and Universities reported problems with accessibility of websites and learning management systems (LMS), accessibility of digital audio and video, time limits built into online exams that are inflexible, PowerPoint/data projection during lectures, course materials in PDF, and adaptive technologies. Students also mentioned technical difficulties while using e-learning and connecting to websites and LMS, problems downloading and opening files (video clips that take too long to download), poor use of e-learning by professors and their own lack of knowledge working with e-learning, and poor accessibility of course notes and materials in many formats. Sixtyseven per cent of students, $53 \%$ of service providers, $36 \%$ of e-learning professionals and $35 \%$ of professors indicated that at least one of their three e-learning problems remained unresolved".

According to Global voices (2020) despite the numerous reforms in education, people with disabilities seems not to be fully given the support needed to maximize their potentials. In the advent of coronavirus where students have to study using virtual learning platforms, researchers' attention was much on working-class students and students in rural areas, but not specifically on students with special needs. A study by Henaku (2020) on COVID-19: Online Learning Experience of College Students: The findings revealed that both social media and online learning platforms were used for teaching and learning by the Colleges of Education in Ghana. It was also found that students experience internet connectivity problems, financial difficulty due to the high cost of internet bundle, challenges with devices and disruption as a result of the need to assist in household production.

Students with hearing and visual impairments in all tertiary education institutions have to resort to the use of Zoom, Telegram, WhatsApp, Podbean, and University Learning Management Systems (LMS) for learning. These digital platforms that were not built for virtual learning for people with visual and hearing disabilities. Many hearing-impaired students were separated from their sign language interpreters who could explain concepts. This especially impacted hearing-impaired students with limited knowledge of sign language. Visually-impaired students on the other hand were separated from their sighted peers who serve as note takers, and provide other support services. A hearing-impaired student in one of the Colleges of Education shared her experiences with e-learning:

Sometimes some tutors will use audio instead of caption. But I am deaf, I can't hear on audio. That means an interpreter is supposed to translate it for deaf people. I have to meet the interpreter through the Zoom app. But unfortunately, we can't meet often due to network connection problems and some phone problems (Global Voices, 2020). 


\section{Statement of problem}

Several studies have been conducted into the use of virtual learning as supplement to face-to-face teaching and learning in the Ghanaian context with few studies on experiences of students in learning virtually (Henaku, 2020). Also, much studies have been carried on challenges facing students in learning Information Communication Technology in Ghana. However, it appears no study have been conducted into the challenges of visually impaired students in learning virtually in Colleges of Education in Ghana. As first time virtual learners, the researchers were instigated to investigate the challenges the visually impaired students face at Wesley College of Education in Ghana.

\subsection{Research questions}

The following research questions were raised to guide the study.

1. How does virtual learning benefit students with visual impairment in Colleges of Education in Ghana?

2. What challenges do students with visual impairment face in the use of virtual mode of learning in Colleges of Education in Ghana?

\section{Methodology}

\subsection{Research design}

The research design adopted for the study is case study. A case study is an in-depth study of a particular research problem rather than a sweeping statistical survey or comprehensive comparative inquiry (Gerring, 2004). It is often used to narrow down a very broad field of research into one or a few easily researchable examples. The case study research design is also useful for testing whether a specific theory and model actually applies to phenomena in the real world. It is a useful design when not much is known about an issue or phenomenon. Yin (2009), view case study as a strategy for doing research which involves an empirical investigation of a particular contemporary phenomenon within its real life context using multiple sources of evidence. A case study focuses on a single unit, such as individual, one group, one organization, or one program. The goal is to arrive at a detailed description and understanding of the phenomenon (Ary, Jacobs, Sorensen, \& Razavieh, 2010). The choice of case study design rest on the research questions formulated for the study and the focus on a single unit, 'challenges of visually impaired students in the use virtual learning platforms'.

\subsection{Population/sample and sampling technique}

The population comprised all visually impaired students from Wesley College of Education. The sample for this study consisted of 4 student teachers who are visually impaired. The purposive sampling technique was used for the study. Purposive sampling is a form of non-probability sampling in which decisions concerning the individuals to be included in the sample are taken by the researcher, based on a variety of criteria. According to Atkinson (2002), the variety of criterion may include specialist knowledge of the research issues, or capacity and willingness to participate in the research. The purposive sampling technique was used in selecting participants because they could provide information needed for the study. The total population was engaged in the study in a form of census due to the limited number.

\subsection{Instruments for data collection}

Semi structured interview guide was used to collect data. Babbie (2007) explained that, questions used in semi-structured interviews tend to be open-ended so that the respondents are at their own will to decide how they will answer questions in terms of the words they use and the length of response they give. Because of its flexible 
nature, semi-structured interview method gives opportunity to the interviewer to ask initial questions followed by probes meant to seek clarification of issues raised. The probes are either pre-stated or posed in the course of the interview process. The flexible nature of semi-structured interview method gives opportunity to the interviewer to ask initial questions followed by probes meant to seek clarification of issues raised. The probes are either pre-stated or posed in the course of the interview process. The use of semi-structured interviews, according to Yin (2009), gives more in-depth understanding of their respondents' thoughts and feelings, and their focus phenomenon, than closed-ended questions.

\subsection{Data analysis}

Analysis of the data was guided by key themes that emerged from the data collected. The process started with transcribing all interviews and highlighting words sentences and thoughts that served as units for more detailed coding. The data was transcribed using thematic analysis. Thematic analysis is the process that identifies analyze and report the occurrence of themes in the data collected from the field (Braun \& Clarke, 2006). The review and restructuring data in order to obtain information that reflect the research questions help to develop a deeper understanding of the problem under study. This process of alternating data collection and data analysis in qualitative studies is known as interim analysis (Miles \& Huberman, 1994).

\section{Results}

\subsection{Benefits of virtual learning to the visually impaired}

Access to learning materials online - On access to learning materials as a benefit of virtual learning, these were some comments made by respondents:

Before we start the online lessons, sometimes the tutors put the lecture notes online that is through our emails and WhatsApp groups and this help us to make advance preparation before lesson start. Even though some of us cannot see so I call some of my friends to read the headings for me. Getting friends to read to us at times is difficult as we stay apart during such instructions unlike the time of face-to-face. (Student Teacher "A")

Another student teacher with visual impairment stated this way:

Apart from our tutors putting the lecture notes in our emails and WhatsApp platforms, some tutors also added sample exams and quizzes questions which was not done in the traditional classrooms and this is an important aspect of using the virtual learning, though it has its own challenges. (Student Teacher "B")

It was evident from the results that tutors upload learning materials in the form of videos, lecture notes, PowerPoint and quiz questions for use by students with visual impairment. However, it is difficult for students with visual impairment to access these materials by relying on peers.

Learners learn at their own pace - This was what two of the respondent said about learning at their own pace:

When the tutors were teaching online, I record the lecture and listen to it at the time I want be it morning, afternoon, evening and dawn. More so, there are times that I am assisted to access the platform after lessons for information. I for instance, I normally listen to audios sent to us by the lectures in the night and this gave me the opportunity to be able to understand the concepts as compare to the traditional classroom where every student is supposed to be in class at the same time and start the lesson together. (Student Teacher "B") 
Another respondent said this:

Virtual learning helps a lot because, I record the lecture and learn the time that I want. You will also not be force to go for lectures even if you are not willing to go as in the case of the traditional classroom situation, because in the traditional classroom situation, can be penalized for not going for lectures. (Student Teacher "C")

Virtual learning support students with visual impairment learn at their own pace at any place they find. This confirm assertions of Arkorful and Abaidoo, (2014) and Fichten et al. (2009) that, the use of e-Learning allows self-pacing where each student study at his or her own pace whether slow or quick. It therefore increases satisfaction and decreases stress.

Reduce fear of talking in the classroom - The study also revealed the virtual learning reduce fear of talking in the classroom because, students are not gathered in one classroom. One of the respondent had this to say:

Sometimes when you are answering or asking question, some students laugh at you but this system has help to reduced it. I could remember that sometime ago a student was about answer question and in the course of speaking he made a grammatical error and most of the students laughed him, since then he never spoke in the class again. (Student Teacher "D")

Another respondent recounted:

Some students shout at you when you are speaking and you make a mistake or even if they think you are delaying, they hoot and make noise but the usage of virtual learning in this semester has reduced it. Especially when it is a last period and left with few minutes for the lecture to end if you don't understand anything and you try to seek for clarification, other students will make noise in other to register their disagreement. (Student Teacher "B")

Findings from the study revealed that, mostly students with visual impairment for fear of being mocked decline responding to questions during face-to-face interactions. However, virtual learning provides them the courage to respond to questions. This concurs Wagner et al. (2008) who espouse that e-Learning makes available extra prospects for interactivity between students and teachers during content delivery.

Access to open learning - On open access to learning, respondents made these comments:

Materials provided by tutors in the course of virtual learning were not enough so this had put pressure on us to search elsewhere for more information rather than solely depending on what the tutor have provided and doing that equipped us to make our own research concerning some topics. (Student Teacher "A")

Another respondent said this:

Previously tutors do provide us with hand out but due to the virtual learning we were not provided this entreat us to search for information from other sources. (Student Teacher "C")

Virtual learning provides student teachers open access to learning where they are not confine to a particular lecture notes but to explore to top up what has been provided by tutors. They also learn from any place at any time.

\subsection{Challenges of students with visual impairment in using virtual learning platforms}

The study revealed the following as challenges of students with visual impairments in the use of virtual learning: difficulty meeting individual learning styles, difficulty with clarification and explanation of concepts, lack of braille version for online instruction, limited access to peer support, poor internet access, unavailability of 
Amaniampong, P., \& Nyavor, M.

learning resources to access materials online and lack of access to virtual platforms.

Difficulty meeting individual learning styles - This was what one of the respondent said:

Every individual has the way he/she learn but the virtual learning does not cater for all these needs making it difficult for some of us to understand what has been taught. This is because some concepts especially the sciences need one on one interaction for better understanding which the virtual lacks. (Student Teacher "C")

Another student teacher said this:

The virtual learning in our situation was one way, making it less interested or interactive as compare to traditional classroom. For the traditional classroom learning, lectures and students sometimes clack jokes in the classroom but virtual doesn't because sometimes students respond or contribute in the discussion by text. (Student Teacher " $\mathrm{D}$ ")

The use of virtual learning inhibits the learning styles of learners. In the face-to-face classroom, teachers adapt instructions and materials to meet the learning styles of each student. However, in virtual classrooms student teachers learning styles and needs are not met as expected. This corroborates Leporini and Paterno (2004) that the web designers tend to address only accessibility issues, and ignore the equally important usability dimension of e-learning tools of the visually impaired.

Difficulty with clarification and explanation of concepts - The student teachers raised concern that virtual learning is less effective in terms of explanation, clarification of concepts. These were some of comments of participants:

In the traditional classroom setting, tutors make a lot of explanations and clarifications to concepts that students find it easy to understand but in virtual learning few explanation and clarifications were done because sometimes WhatsApp is used a mode of delivery. (Student Teacher "C")

Another respondent remarked:

The tutors sometimes used WhatsApp for the lectures but some of us cannot see, these methods affect us a lot. When you want to find out something from our friends, they sometimes raised concern that they themselves did not understand some of the concepts because the tutor was using WhatsApp. (Student Teacher “D”)

It was clear from the results that visually impaired students have difficulty understanding concepts. Mostly clarifications and explanations of concepts is a challenge to the visually impaired students. This means students get clearer explanations form face-to-face interactions than virtual.

Lack of braille version for online instruction - All the respondents raised concern with lack of braille version on online instruction as one of the challenges. This was what one said:

We students with visual impairment depend solely on the use of braille in reading and writing but all materials put on the platforms were not braille to compensate those of us who have difficulty learning virtually or consolidate what has been taught. This is one of our great challenge l for instance raised concern about it but I was told this was the beginning and something will be done about it as we progress but nothing was done. (Student Teacher "A")

Other respondents stated these:

Everything that we do in terms of learning and writing of our exams and quizzes depend on the braille but the virtual learning does not make room for that making our learning difficult.

28 Consortia Academia Publishing (A partner of Network of Professional Researchers and Educators) 
(Student Teacher "B")

In the normal classroom learning, our reading materials were brailed for us but the virtual learning does not provide that, we solely depend on the audio means of learning and this makes the learning one way, boring and sometimes difficult to understand. (Student Teacher " $\mathrm{C}$ ")

Students with visual impairment have rely on braille version of instructions and expect to be given such to complement what has been taught online. The braille version is to augment challenges students have in accessing virtual platform. However, students are not provided with such materials to aid their studies.

Limited access to peer support - These were some comments of the respondents:

During face-to-face instructions, our friends in the same classroom gave support by explaining concepts to us which make our learning easy as compare to the virtual learning where every student is at his/her home. On campus, we formed groups and meet regularly for our assignments and discussion which make learning easy because it is in the group discussion that you can asked question and get the needed answer. (Student Teacher "C")

Peer support is very important in every academic endeavor but we students with visual impairment lost that opportunity during the virtual learning. (Student Teacher "D”)

Peer support has been paramount to the visually impaired. However, during online studies where students stay apart, it is difficult for students with visual impairment to access the support of their sighted peers which affect their use of virtual learning platforms. Visually-impaired students on the other hand were separated from their sighted peers who serve as note takers, and provide other support services (Global Voices, 2020).

Poor internet access - Respondents raised concern with poor internet access as on one of the challenges of virtual learning. These were some of their comments:

I sometimes had problem with the internet, this sometimes occur for sometimes thirty or sixty minutes before you will be able to connect it. I frequently experience these challenge during the online quiz. (Student Teacher "B")

This is one of the challenges I experience during the virtual learning. This really affected me because sometimes when the lecturers were teaching, I find it difficult to hear due to internet problem. Some times when student asked questions and the lecture is answering, we find it difficult to hear due internet problem. (Student Teacher "C")

Again, one of the challenges visually impaired students raised is poor internet access. Poor internet access hinders student access to virtual learning platforms. This is in agreement with Henaku (2020), study that students experience internet connectivity problems, financial difficulty due to the high cost of internet bundle in the use of virtual platforms for teaching and learning.

Unavailability of learning resources to access materials online - In response to availability of resources in support of virtual learning, participants had this to say:

Most of us don't have computers to access the platforms neither have android phones that could support our learning. It was later that T-TEL supported some of us with phones which was getting to the end of the semester. Sometimes our phones develop fault which affect our access to the virtual learning platforms. (Student Teacher A, B, C, and D)

Resources which could help student teachers access virtual learning platforms are inadequate and some non-functional. This concurs Sarker, Mahmud, Islam, and Islam (2019) that inadequate ICT infrastructure is a challenge capable of hindering e-learning implementation success. 
Lack of access to virtual platforms - The interfaces of the virtual learning platforms sometimes are in accessible to us the visually impaired. We find it difficult to navigate the platforms making us not to fully benefit from the instructions (All participants). Virtual platforms mostly not accessible to visually impaired due to some of the interfaces on the web pages. This agrees with Craven and Brophy (2003), Gerber (2003) and Leporini and Paterno (2004) that much transformation in universal access to technology has been made. However, students with visual impairment still struggle with poorly designed computer interfaces that continue to lag behind in some web design features. American Foundation for the Blind (2008) indicated that features of online educational tools pose significant problems for those using assistive technology such as screen reading or screen magnification software.

\section{Conclusion and recommendation}

The study focus on the challenges of visually impaired students in the use of virtual learning platform at Wesley College of Education. The study concluded that, students have access to learning materials online, learners learn at their own pace, virtual learning reduce fear of talking in the classroom and provide access to open learning. These were some of the benefits of virtual learning to students with virtual impairment. Notwithstanding, the study also revealed that student with visual impairment faced challenges in the use of virtual learning platform. These include, virtual platform not catering for individual learning styles, students have problem with clarifications and explanations of concepts, lack of braille version of online instructions, inadequate resources or facilities to access online instructions and poor internet access. These may affect the performance of student teachers since the quizzes and assignment were done online. It may also implicate tutors for inappropriately using the virtual platform in teaching. It was recommended that tutors should provide student teachers with braille version of their lecture notes online to compensate for those who have difficulty to access the system, explain concepts to and provide assign peers who could support the visually impaired in their studies, make sure interfaces of virtual learning are visually impaired friendly with minimal graphics that could hinder access, and tutors varying their mode of delivery to meet the learning styles of learners.

\section{References}

Akorful, E., \& Abaidoo, N. (2014). The role of e-learning, the advantages and disadvantages of its adoption in higher education. International Journal of Education and Research, 2(12) 397-410.

American Foundation for the Blind. (2008). Distance learning: How accessible are online educational tools. https://www.afb.org/blindness-and-low-vision/your-rights/technology-and-information-accessibility/dist ance-learning-how

Andersson, A. (2008). Seven major challenges for e-learning in developing countries: Case study eBIT, Sri Lanka. International Journal of Education and Development using Information and Communication Technology, 4(3), 45-62.

Ary, D., Jacobs, L. C., Sorensen, C., \& Razavieh, A. (2010). Introduction to research in education. Cengage Learning.

Atkinson, R. K. (2002). Learning from examples: Instructional principles from the worked examples research. Mississippi State University.

Babbie, E. R. (2007). The practice of social research. Thomson Wadsworth.

Bouchard, P. (2011). Network promises and their implications. The impact of social networks on teaching and learning. Revistade Universidad y Sociedad del Conocimiento, 8(1), 288-302. https://doi.org/10.7238/rusc.v8i1.960

Braun, V., \& Clarke, V. (2006). Qualitative research in psychology: Using thematic analysis in psychology. Routledge. https://doi.org/10.1191/1478088706qp063oa

Craven, J., \& Brophy, P. (2003). Non-visual access to the digital library: The use of digital library interfaces by blind and visually impaired people. Library and Information Commission Research Report No.145. https://www.researchgate.net/publication/27398681_Non-visual_access_to_the_digital_library_NoVA_t 
he_use_of_digital_library_interfaces_by_blind_and_visually_impaired_people

Fichten, C. S., Asuncion, J. V., Barile, M., Ferraro, V., \& Wolforth, J. (2009). Accessibility of e-learning and computer and information technologies for students with visual impairments in postsecondary education. Journal of Visual Impairment \& Blindness, 103(9), 543-557. https://doi.org/10.1177/0145482X0910300905

Gedera, D. S. P, \& Williams, P. J. (2013). Using activity theory to understand contradictions in an online university course facilitated by Moodle. International Journal of Information Technology and Computer Science (IJITCS), 10(1), 32-40.

Gerber, E. (2003). The benefits of and barriers to computer use for individuals who are visually Impaired. Journal of Visual Impairment \& Blindness, 97, 536-551. https://doi.org/10.1177/0145482X0309700905

Gerring, J. (2004). What is a case study and what is it good for? American Political Science Review, 98(2), 341-354. https://doi.org/10.1017/S0003055404001182

Global Voices. (2020). How COVID-19 affects education for people with disabilities in Ghana. https://globalvoices.org/2020/07/03/how-covid-19-affects-education-for-people-with-disabilities-in-gha $\underline{\text { nal }}$

Hameed, S. Badii, A., \& Cullen, A. J. (2008). Effective e-learning integration with traditional learning in a blended learning environment. European and Mediterranean conference on information system (pp. 25-26).

Henaku, A. E (2020). Online learning experience of college students: The case of Ghana. International Journal of Multidisciplinary Sciences and Advanced Technology, 2(1), 54-62.

Herriot, T. K. (2006). An increasingly diverse student population: a rationale for consideration of universal access at postsecondary institutions. In P. Hernon \& P. Calvert (Eds), Improving the quality of library services for students with disabilities (pp. 45-56). Libraries Unlimited.

Kharbach, M. (2013). 14 technology concepts every teacher should know about. https://www.educatorstechnology.co

Leporini, B., \& Patemo, F. (2004). Increasing usability when interacting through screen readers. Universal Access in the Information Society, 5(1), 57-70. https://doi.org/10.1007/s10209-003-0076-4

Miles, M. B., \& Huberman, A. B. (1994). Qualitative data analysis: An expanded source book (2nd ed.). Sage.

Oye, N. D., A. Iahad, N., Madar, C., \& Ab. Rahim, N. (2012). The impact of e-learning on students' performance in tertiary institutions. IRACST - International Journal of Computer Networks and Wireless Communications (IJCNWC), 2(2), 122-130.

Pelet, J. E., \& Lecarte, B. (2013). Virtual worlds as the next asset of virtual learning environment for students in business? International Journal of Virtual and Personal Learning Environments, 3(2), 59-76. https://doi.org/10.4018/jvple.2012040104

Sarker, M. F. H., Mahmud, R. A., Islam, M. S., \& Islam, M. K. (2019). Use of e-learning at higher educational institutions in Bangladesh: Opportunities and challenges. Higher Education Journal of Applied Research, 11(2), 210-223. https://doi.org/10.1108/JARHE-06-2018-0099

Schutt, S., \& Linegar, D. (2013). We learn as we go: What five years playing with virtual worlds has taught us. International Journal of Virtual and Personal Learning Environments, 4(2), 124-136. https://doi.org/10.4018/jvple.2013040107

Smedley, J. K. (2010). Modelling the impact of knowledge management using technology. Operational research society, 23(4), 233-250. https://doi.org/10.1057/ori.2010.11

Wagner, N., Hassanein, K., \& Head, M. (2008). Who is responsible for e-learning in higher education? A Stakeholders' Analysis. Educational Technology \& Society, 11(3), 26-36.

Weller, M. (2010). The centralization dilemma in educational IT. International Journal of Virtual and Personal Learning Environments, 1(1), 1-9. https://doi.org/10.4018/jvple.2010091701

World Health Organization. (2019). Blindness and vision impairment. https://www.who.int/news-room/fact-sheets/detail/blindness-and-visual-impairment

Yin, R. K. (2009). Case study research: Design and method (4th ed.). Sage. 
Amaniampong, P., \& Nyavor, M.

32 Consortia Academia Publishing (A partner of Network of Professional Researchers and Educators) 